\title{
Biomass bale stack and field outlet locations assessment for efficient infield logistics
}

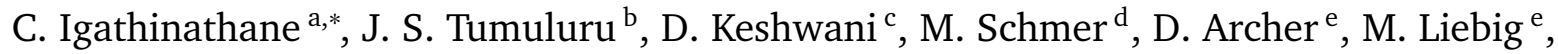 \\ J. Halvorson ${ }^{\text {e }}$, J. Hendrickson ${ }^{\mathrm{e}}$, S. Kronberg e \\ ${ }^{a}$ Department of Agricultural and Biosystems Engineering, North Dakota State University, 1221 Albrecht Boulevard, \\ Fargo, ND 58102, USA \\ ${ }^{b}$ Biofuels and Renewable Energy Technologies Department, Idaho National Laboratory, 750 University Blvd., Idaho \\ Falls, ID 83415-3570, USA \\ ${ }^{c}$ Department of Biological Systems Engineering, University of Nebraska-Lincoln, 215 L. W. Chase Hall, East Campus, \\ Lincoln, NE 68583, USA \\ ${ }^{d}$ USDA-ARS-AMRU, 251 Filley Hall/Food Ind. Complex, University of Nebraska-Lincoln, East Campus, Lincoln, NE \\ 68583, USA \\ ${ }^{e}$ Northern Great Plains Research Laboratory, USDA-ARS, $170110^{\text {th }}$ Avenue SW, Mandan, ND, 58554, USA
}

\section{Abstract}

Harvested hay or biomass are traditionally baled for better handling and they are transported to the outlet for final utilization. For better management of bale logistics, producers often aggregate bales into stacks so that bale-hauling equipment can haul multiple bales for improved efficiency. Objectives of this research include simulation of bale collection logistics after forming subfield stacks, evaluation of location effects of bale stack and field outlet, the number of stacks, transported bales/trip, and other field parameters on logistics distances (aggregation, transportation, and total). The software ' $\mathrm{R}$ ' was used to perform the simulation, statistical analysis, and data visualization. Formation of bale stacks decoupled aggregation and transportation components. Stacks formation thus allows for aggregation and transportation to be performed at different times. Increasing the number of subfield stacks and the number of transported bales/trip significantly reduced the total logistics distances. The order for the best bale stack and outlet locations was: middle, near middle, mid-edge along the length, mid-edge along the width, and finally, corners. Except for swath and windrow variation, the studied field variables had a highly significant influence on the logistics distances. Increased bales/trip $(\geq 6)$ reduced the variations of outlet locations. Locating the field outlet at or near the center of the field along

*Corresponding author. Tel.:+1 701667 3011; fax:+1 7016673054.

E-mail address: Igathinathane.Cannayen@ndsu.edu (C. Igathinathane) 
with an appropriate number of square subfields with stacks at the middle, and increased bales/trip will be the most efficient strategy.

Keywords: Bioenergy feedstocks, Biomass utilization, Farm machinery, Field operation, Infield storage, Renewable energy

\section{Introduction}

Global demand for high-quality hay and biomass is on the rise to cater to the cattle and dairy industries along with biomass applications, which calls for improved efficiency. About $95 \%$ of this increased global demand for U.S. hay has been supplied by the western states. Coupled with local demands, the hay prices were doubled in the last 10 years with reference to 2015 [1]. Although there was a slight decline in the past few years, U.S. hay annual production in 2014 (including alfalfa) was $126.8 \times 10^{6} \mathrm{Mg}$ on a planted area of $231 \times 10^{3} \mathrm{~km}^{2}$ [2]. With the thrust on the biomass-based, clean, renewable fuel and products, additional demand appears for biomass in the form of hay, dedicated energy crops, and agricultural and forest residues. This increasing demand coupled with higher prices represents a huge economic value for these crops. Thus, the efficiency of every component of field operations, including infield bale aggregation and transportation logistics, becomes essential for managing farm enterprises.

Baling of harvested material in the field is a traditionally followed practice for efficient handling of loose hay and biomass. The bales formed in the field need to be transported to the outlet for utilization or dispatch. Biomass supply analysis, in general, has assumed that bales are directly transported to the final destination, or aggregated at a field edge before transport off-site, or collected with self-loading wagons in the field for immediate transport off-site [3]. However, to better manage the bale collection, producers often aggregate bales within a field into stacks before transporting to an outlet location for final use (Fig. 1). The underlying motivation for forming subfield stacks is to aggregate bales into groups, sized for bale-hauling equipment, that can haul multiple bales in one step to a field outlet, making the logistics efficient. 
[Fig. 1 about here.]

The cropping sequence necessitates the timely infield bale logistics; therefore, bale aggregation and transportation can be viewed as an operation of clearing the field for next crop. For example, with wheat straw or corn stover, it may be beneficial if bales are moved immediately off of the field and not be left in subfield stacks (especially for stover) for long. With corn stover and similar crops, the harvest window is short and access to the bales is vital before field conditions become undrivable. Also, wheat and corn producers may want the balelogistics completed as soon as possible in order to plant cover crops, apply fall nitrogen fertilizers, and perform other management practices. Therefore, any efficiency in the infield bale logistics is always beneficial.

Some of the biomass logistics related research include: development of simulation of switchgrass collection, storage, transport and preprocessing in a feedstock supply chain using an integrated biomass supply and logistics (IBSAL) model and its implementation [4, 5]; network of regional lignocellulosic preprocessing centers [6]; corn stover supply logistics system [7]; large capacity transport of bales to minimize hauling cost of herbaceous biomass [8]; economics of corn stover supply for fuel ethanol conversion [9]; eight different corn stover logistics systems modeled to identify the lowest cost feedstock system [10]; logistics infrastructure for biomass delivery to biorefinery with the concept of satellite storage location [11]; and advanced operations research (OR) applications for vehicle routing problem for agricultural equipment logistics being researched to provide optimized least-cost routes [12, 13, 14].

Studies specifically on hay/biomass bales logistics include: development of a MATLAB training tool on the timing, distance and pattern of moving, handling and storing round bales with a self-loading wagon [15]; hybrid genetic algorithm solution for the efficient bale collection routes with a wagon handling multiple (15 and 35) bales [16], which serves as an example of advance operations research application in this field; and simulation of the bales layout mimicking the baler operation, evaluation of several infield biomass bales aggregation strategies, and the effect of various field parameters on bales logistics [17]. Thus, the literature search 
indicated that studies related to bale stack formation and the role of bale stacks on infield logistics were lacking.

Modern agricultural practices always look for performing field operations in an effective manner. Developing efficient aggregation scenarios with subfield stacks for existing hay crops and future bioenergy crops is expected to result in savings in terms of labor, time, fuel costs, and other resources.

The specific objectives of this research effort were to: (1) develop a simulation of a biomass baler for layout of bales on the field; (2) delineate subfields and form bale stacks in desired layouts; (3) perform bale logistics operations involving aggregation of bales to stacks and bales transportation to the field outlet for various bale stack and field outlet locations; and (4) determine the effects of field size, field shape, harvester swath, biomass yield, bale mass, biomass windrow variation as well as number of subfield stacks and number of bales transported per trip on the collection logistics distances.

\section{Materials and methods}

\subsection{Overall simulation strategy for bales infield logistics}

The overall strategy of the simulation can be summarized as four operations: (1) form the bales based on the bale pickup length along windrow, (2) divide the field into subfields for bale aggregation, (3) aggregate the bales into subfield stacks, and (4) transport bales from the subfield stacks to the field outlet. The simulation also includes studying the effect of the number of subfield stacks, their distribution layout with respect to the outlet, location of the outlet with respect to the field, and various field variables that affect the bale formation and eventually the collection logistics.

In this study, bale aggregation assumes moving single bale per trip (common tractor operation) to a field stack or outlet. The operation should be repeated for all bales to complete the logistics. Even though two or three bales can be handled by a tractor with modern attachments, or even more bales using automatic bale pickers, a single bale aggregation was considered in 
the study to represent the basic equipment and this will provide the necessary insight for the bales logistics. As the motivation for forming subfield stack was to aid bale-hauling equipment operations, transportation simulations assuming various numbers of multiple bales/trip were also studied. A reference (control) method of aggregating all the infield bales directly to the field outlet was considered for comparison with other strategies. The coding for the simulation, data analysis, and visualization was developed using the ' $R$ ', the statistical analysis package $[18]$.

\subsection{Bale formation and bales layout simulation on field}

Coordinates of individual bales, necessary for the bale logistics analysis, were simulated by mimicking the operations of the baling [17]. The amount of biomass collected by the baling equipment while forming the bale from the windrow was a function of the bulk density of biomass and bale mass. The yield variation, existing in the field, was simulated through a factor that affected the windrow pickup length and altered the bale layout spacing. Thus, baling the biomass along the windrows and traversing the entire field simulated the layout of bales on the field in a specific pattern and their coordinates were recorded for analysis. The method of determining the field dimensions, number of bales, bale pickup length, subfield allocation for stacks as well as subfield stacks formation at various strategic locations (for example, see Fig. 3) are presented in Supplementary material.

\subsection{Subfield stack bale aggregation and field outlet transportation}

In this study, all bale movements (aggregation or transportation) were considered to be along a straight line path. Thus, the sum of linear (Euclidean) distances of all subfield bales to the subfield stack represents the total aggregation distance, and that from subfield stacks to field outlet represents the total transportation distance. Only these direct (one-way) distances were used in the analysisbut were sufficient to provide the data required for scenarios comparison. However, to obtain the actual working distances these one-way distances need to be multiplied by two to account for the to-and-fro movement of the equipment. 


\subsection{Statistical data analysis}

The statistical analysis package ' $\mathrm{R}$ ' [18] was used to perform the statistical analysis. Two-way ANOVA was performed to test the variation between levels of independent variables, such as field outlet and stack location, the number of subfield stacks, the number of transported bales/trip, and the various field parameters. The various logistics distances (aggregation, transportation, and total) formed the dependent variables. Process simulation, data processing, statistical analysis as well as the graphical outputs were coded in ' $R$ ' using appropriate packages (e.g., 'base', 'ggplot2', 'grid', 'reshape2').

\section{Results and discussion}

\subsection{Effects of subfield stack locations along specified paths on aggregation distances}

Bale aggregation to a specified location in the subfield represents the formation of subfield stacks. Different locations of stacks in the subfield can be simulated along simple pathsand the resulting effect on bale aggregation distances can be studied to find the optimum aggregation location. To illustrate the subfield stack location effect (also applicable to field outlet) on bale aggregation distances, stacks were moved along selected linear paths in a rectangular field $(L / W=2)$ of 64.75 ha, and the results are presented in Figure 2.

[Fig. 2 about here.]

The simulated field was $569 \mathrm{~m}$ wide and $1138 \mathrm{~m}$ long and its centroid coincided with the middle of the field (284.5, $569 \mathrm{~m}$; not plotted). Total aggregation distances of the bales (total 1295) along these selected linear paths at 50 locations were studied (Fig. 2). In general, a parabola-shaped variation, which was symmetrical, was obtained when the paths were along the field boundary ( 0 to $W$ or 0 to $L$ ) and along the diagonal ( 0 to $W, L$ ). The variations were not symmetrical when the stack location paths were from the origin to the mid-length (0 to $W, L / 2$ ) or mid-width (0 to $W / 2, L$ ) because these paths did not divide the field symmetrically or run completely along the edges. 


\subsection{Ranking of collection path aggregation distances}

The minimum aggregation distance was obtained when the collection point was closer to the field centroid (Fig. 2). Any path that approached the centroid produced the minimum aggregation distance. Therefore, the diagonal path ( 0 to $W, L)$, where it intersected with the centroid, gave the least aggregation distance. Paths along the width had increased aggregation distances at the field ends and were reduced towards the midway $(-10.7 \%)$. Paths along the length followed a similar trend but produced higher reduction $(-35.9 \%)$ compared to the endpoints. These trends occurred because the path along the width boundary is farther away from the centroid compared to that along length boundary, on a rectangular field. Similarly, the path to the mid-length (closer to 0 to $W$ path) produced slightly less reduction $(-44.3 \%)$ than that to mid-width (closer to 0 to $L$ path; $-47.0 \%$ ). But the path through the centroid (diagonal) produced the maximum reduction $(-50.4 \%)$. Similar trends are expected with other field sizes and shapes such as square. However, for other shapes, such as quadrilateral, and circular and semi-circular (central pivot irrigation systems), the developed simulation will not work, as the field boundaries continuously vary and harvesting patterns differ with these shapes. A future simulation study may be required to address these shapes having various harvesting patterns.

These results indicate that the best locations for the subfield stack or field outlet are: (1) field center, (2) near the field center, (3) mid-length, (4) mid-width, and (5) field corners. For square fields or subfields, the mid-length and mid-width aggregation results coincide.

\subsection{Effects of subfield stack and outlet locations on logistics}

Following the collection path aggregation results (Fig.2), the different layouts of subfield stacks and outlets were considered for logistics evaluation (Fig. 3). Collection logistics distances of the various scenarios (Fig. 3a-d), evaluated for a square $(L / W=1)$ and rectangular $(L / W=2)$ fields, are presented in Figure 4.

[Fig. 3 about here.]

[Fig. 4 about here.] 
Total aggregation distances diminished from the diagonal corner (D) to the field middle (M), as were ranked earlier (Fig. 2). The mid-width (W) and mid-length (L) demonstrated similar aggregation values for a square field but continuous reduction with a rectangular field (Fig. 4). Aggregation only considers one bale per trip (no variation with bales/trip). Only the transportation distance varies according to the number of bales/trip. Compared to the reference method applied to corner outlet (O:D; shown as dotted line in Fig.4), the aggregation distances reduced by 30\%. Rectangular fields require increased logistics distances because the collective distances of the bales from any point is greater than that of the square field. This can also be seen from the increased perimeter of the rectangular field (3414 $\mathrm{m}, L / W=2$ ) compared to a square field ( $3218 \mathrm{~m}, L / W=1$ ) of the same area of 64.75 ha.

Compared to aggregation, transportation had an opposite increasing trend among the subfield stack locations (Fig. 4). Also transportation had a clear reduction with increased bales/trip. The reduction effect on the transportation distances was greatest as bales were increased from from one to two bales/trip, then the rate of reduction decreased, and further changes were not appreciable after 12 bales/trip. The total transportation distances of bales, from the subfield middle (M) to the corner outlet in all cases were higher than that from the other subfield locations (D, W, and L).

Total logistics distance, the sum of aggregation and transportation, followed an increasing trend only with single bales/trip scenario among the subfield stack locations (Fig.4). However, with increased bales/trip the trend was decreasing that was comparable to aggregation. This observation indicates that the aggregation component is more influential than transportation, when the number of bales/trip is more than one. Rhe advantage of making subfield stacks can be realized starting from two bales/trip onwards in transportation for both shapes of the field. Hauling of multiple bales $(\geq 2)$, especially 2 to 6 bales using trailers is highly practicable in the present modern farm operations.

Thus, the best method of infield logistics is to aggregate the bales into stacks at the middle of each subfield and then haul two or more bales to the field outlet as shown in Fig. 3d, or 
to other outlets (Fig. 3e). Aggregating the bales to the middle (M) and transporting them back to field corner (O:D) may involve some negative movement (bales moved away from O:D during aggregation), but the distance saved in aggregation to the middle (Fig. 2) outweighs the negative movement of some bales. Compared to the corner field outlet (Fig. 3d), more savings in total logistics are expected with other field outlet layouts (Fig. 3e). If the operations allow only single bales/trip then the best strategy is the reference method of direct aggregation to the field outlet. However, bale aggregation into stacks at subfield corners for the field corner outlet, subfield mid-edge to field mid-edge outlet, and so on, is the next best strategy (Fig.4).

3.4. The effect of stack locations along selected diagonal path on the total distance to field outlets The diagonal path ( 0 to $W, L$ ) resulted in the best stack location, namely the middle (M), for aggregation (Fig. 2), and transportation from middle of subfields to other outlets (D, W, L, and M) was efficient as well, when the number of bales/trip was $\geq 2$ (Fig. 4). However, it is worthwhile to investigate the relocation of field stacks along the best aggregation diagonal path to derive possible advantage in the total logistics distances (Fig. 5). Overall, when 6 bales/trip were assumed, the total distance trends tended to coincide with the total aggregation, because the transportation component is relatively small when a larger number of bales/trip were considered. However, the trends with single bales/trip were different and were characteristic of the field outlets considered. For single bales/trip to outlet O:D, the total distance increased as the stack moved along the diagonal from D. For other outlets, the total distance initially decreased and then increased as the stack moved from $\mathrm{D}$ along the diagonal, but the lowest total distance differed based on the outlet (Fig.5). The observed decrease was due to the closer placement of stack with respect to the outlet when it was moved from D diagonally initially. Once the minimum was reached, further movement of the stack resulted in increased total distance and the trends, similar to aggregation (Fig. 2), were parabolic.

[Fig. 5 about here.]

With single or other reduced number of transported bales/trip, the total logistics were observed to deviate highly from the lowest total distance (optimum) location, but this deviation 
was not that high with increased $(\geq 6)$ bales/trip (Fig. 2). The optimal location moved towards the field middle $(\mathrm{M})$ as the number of bales/trip increased. For a middle outlet O:M, the optimized stack location coincided with M, irrespective of bales/trip; but for other outlets, it shifted towards the middle at rates based on the distance of the outlet from the diagonal path. However, with increased bales/trip, the optimized bale stack location, which produced the least total logistics distance ( $y$-axis), was in the range of $22^{\text {nd }}$ to $25^{\text {th }}$ of 50 divisions ( $x$-axis) arbitrarily considered (Fig. 5). This result clearly indicated that the optimum location for the bale stack was the field middle when the bales/trip $\geq 6$.

\subsection{The effect of number of subfield stacks and transported bales/trip on logistics}

Generally, total logistics distances were reduced with both number of subfield stacks (Fig. 6a) and bales/trip (Fig. 6b) for a square field with different field outlets. Aggregation was reduced with increased number of subfield stacks and would equal zero when the number of stacks were equal to the number of bales. Aggregation by principle is not affected by the outlet location, hence, all field outlet trends coincided. With the number of subfield stacks, the transportation distances showed a gradual increase after 16 stacks, as more number of stacks meant more dispersion and increased distances. However, with increasing bales/trip, the transportation distances reduced drastically initially, but less so after 6 bales/trip for all the three outlets.

[Fig. 6 about here.]

All logistic distances were reduced in the order of middle, mid-edge, and corner outlets. Therefore, using smaller equipment, a middle subfield stack location with 6 bales/trip, and 16 subfields for a 64.75 ha field appears to be an efficient combination. Alternatively, increased number of stacks and bales/trip will also be efficient provided the operations allow for such expansions (Fig.6).

\subsection{Overall bale collection logistics and statistical analysis}

The influence on bale collection logistics and their components by the various factors, such as bale stack and field outlet locations, with selected number of subfield stacks and number of 
bales/trip for a rectangular field is presented in Figure 7. The field outlets exerted a notable effect on the logistics distances, with the least distances on middle, followed by mid-length, mid-with, and finally the corner.

[Fig. 7 about here.]

As seen earlier (Fig. 6a), the logistics distances, namely aggregation and total demonstrated a reduction, while transportation responded with a mild increase or flat profile with increased number of subfield stacks from 1 to 25 . Variation of the total, although above the reference method when bales/trip $=1$, received a logistics benefit from bales/trip $=2$ onwards. In all scenarios, aggregating bales to the subfield middle (M) as well as forming more stacks were found to be efficient for all outlets (Fig. 7). Also, when the bales/trip $=6$ or greater, the outlet location will be inconsequential as the total distance variation was less among the outlets. A similar but less pronounced variation of logistics distances (Fig.4) occurred with a square field. The two-way ANOVA (Data of Fig. 7; Supplementary material: A5) of the aggregation, transportation, and the total distances among the independent parameters, such as outlet (4) and stack (4) locations, the number of subfield stacks (3), and bales/trip (8) showed highly significant statistical differences $(p \leq 0.001$ ) in general (Table 1 ). These differences indicated that the logistics distances were significantly affected by the studied changes in the independent variables, which implied the existence of optimal levels. However, aggregation with its assumption of single bale operation was not affected by outlet location and bales/trip. Transportation having similar or, in general, no variation among the stack location was also not statistically significant $(p=0.57)$. The fact that the total logistics varied significantly among all the scenarios indicated the potential for significant saving in logistics by correct choice of levels of parameters studied (Table 1).

[Table 1 about here.]

3.7. The effect of field variables on bale collection logistics 
Variation in the field variables, such as field area, field shape $(L / W)$, harvester swath, biomass yield, bale mass, and biomass windrow variation on the logistics distance was evaluated for a corner outlet (O:D) and stacks at subfield middle ( $\mathrm{M}$ - considered for their best performance). The differences of the total logistics distance from reference method (TotDif, \%) of the three subfield stacks $(9,25$, and 100) are also presented in Table 2 as an example. Other than the field variable studied, the rest of the variables were kept constant.

[Table 2 about here.]

Logistics distances increased with area, $L / W$, and biomass yield; decreased with bale mass; and were not affected by harvester swath and windrow variation (Table 2). Square fields tended to be more efficient logistically than rectangular $(L / W \geq 2)$. The benefit of having an increased number of bale stacks, from reference (control) to 9, 25, and 100, was also evident. On the whole, the total logistics difference was similar. Among the various field variables they were about $-66.2 \%,-71.3 \%$, and $-72.4 \%$ for 9,25 , and 100 subfield stacks, respectively (Table 2).

\subsection{Expended time in bale collection logistics}

The reference or control method (subfield $=1$, and bales/trip $=1$ ) had only a combined aggregation component that indirectly included transportation, hence required more logistics distance and more time to complete. However, with subfield stacks, decoupled aggregation can be performed in a shorter time, and the transportation can occur later. The theoretical distances presented should be multiplied by two to accommodate the to-and-fro movement of the equipment during operations to obtain practical operation times. For example, assuming a $8 \mathrm{~km} \mathrm{~h}^{-1}$ speed of the tractor used in collection and $8 \mathrm{~h} \mathrm{day}^{-1}$ for a 64.75 ha field it takes about 10.4 days $(332.8 \times 2 \mathrm{~km})$ for the reference method. However, with 25 subfield stacks at 6 bales/trip, the aggregation time will be just 1.04 days $(33.2 \times 2 \mathrm{~km})$, the transportation time will be 1.96 days $(62.7 \times 2 \mathrm{~km})$, with 3.0 days of total time. This means the aggregation time is $90 \%$ less, and total time is $71.2 \%$ less than the reference (Table 2). These calculations are 
based on transportation to corner outlet (O:D) with 6 bales/trip, and even more reduced times are possible with other outlets (O:W, O:L, and O:M), if the operations allow for the layout of such outlets, and increased bales/trip.

These results were compared with one of the few previous reports [17]. For a similar field size (65 ha, square) with 955 bales, the reference method took $146.4 \mathrm{~h}$ (18.3 d), while "PickerMin-6" method (automatic 6-bale picker collecting bales and transporting to outlet) took $26.5 \mathrm{~h}$ (3.3 d) [17]. However, in the present work with an increased number of bales to 1080, the reference method used $166.1 \mathrm{~h}(20.8 \mathrm{~d}, 664.5 \times 2 \mathrm{~km})$, and the stack method (O:D-S:25, Fig. 7) used $45.9 \mathrm{~h}(5.7 \mathrm{~d}, 183.6 \times 2 \mathrm{~km}, 25$ stacks). On a 100-bale basis, the reference method of both studies required about $15 \mathrm{~h}$, while the "PickerMin-6" needed about $2.8 \mathrm{~h}$. In comparison, the present study's 25 stacks with 6 bales/trip required about $4.3 \mathrm{~h}$. In this instance, the automatic 6-bale picker method is more efficient $(\approx-35 \%$ of total distance) as it avoids negative bale transport, handles multiple bales in aggregation, and dealt with less number of bales in this case. However, its use requires additional expenditure for the equipment. A rigorous integral study with simulation program development to mimic the automatic multi-bale picker and comparing its logistics efficiency with bale stack formation with simpler equipment deserves to be pursued in the future and that will help verify the results. However, the present method is not far behind in terms of efficiency only requiring a field truck for multiple bale transportation and allowing an advantageous decoupling of the component operations.

Decoupling aggregation and transportation through subfield stacks operation may be advantageous because these operations can then be performed at two different times. For example, contractors can be employed only for aggregation and it can be completed quickly. Under such a scenario, it would be better to group more stacks at the middle of each subfield based on the field size, because aggregation distances, being most dominant, were inversely proportional to the number of subfield stacks (Fig. 6a). After subfield stack formation, transportation can be performed later using high capacity bale hauling trucks/trailers. When this strategy is employed, it is better to have more subfield stacks. 


\subsection{Field outlet location and recommendations}

Bale collection logistics analysis indicates that the field middle (centroid) is the best location for the field outlet. If this option is not available then other locations in the field closer to centroid will be the next choice, followed by mid-edges on the boundary (length first then width), and finally, at the field corners. The strategic location of field outlet becomes more advantageous when the fields are large because producers often divide larger fields into blocks for better management. With such divisions and formed pathways, it makes more sense to locate the field outlet as well as farmstead near the field center. If farm roads are already existing (e.g., connecting field edge to the middle), then they can be taken advantage of while establishing the field outlet. Thus, larger fields and existing roads support central outlet and make logistics efficient. For smaller fields, with fewer bales to deal with, it makes sense to simply follow the reference method of directly aggregating the bales to the outlet.

Farmsteads are usually set at some distance from the geometrical field edge or corner (setback) and will rarely be located in proximity to the field boundary or corner. Any amount of setback from the boundary will have a positive effect on the collection logistics. Thus, if the setback distance is made large enough, it represents a situation approaching the ideal location (viz., center of the field) for the for outlet. When new farm layouts are made, this option of central outlet location should be given a consideration.

\section{Conclusions}

Formation of subfield stacks allows for decoupling of aggregation and transportation components, leading to more efficient infield logistics operation because these operations can be performed at different times. When bale aggregation is performed directly without subfield stacks, the logistics advantages will be lost. An increased number of subfield stacks and number of transported bales/trip reduced the total logistics distance and should be taken advantage of. Logistically square shaped subfields are more efficient than rectangular. The best bale stack location on 
subfields as well as the outlet for the whole field were ranked: middle (e.g., $-50 \%$ from corner), near middle, mid-edge along length - longer dimension (-36\%), mid-edge along width shorter dimension $(-11 \%)$, and corners $(0 \%)$. Field variables, such as field size, field shape, biomass yield, and bale mass, except for the harvester swath and windrow variation, had a significant influence on the logistics distances (aggregation, transportation, and total). Total logistics distance was significantly $(p<.001)$ influenced by the location of stacks and outlet, the number of stacks, and the bales/trip. Fixing the field outlet at or near the center of the field and establishing a transportation road/pathway along with the appropriate number of square subfields with stacks at the middle will lead to the most efficient bale collection logistics in terms of reduced distances and time expended. With increased number of bales/trip (e.g., $\geq 6$ ), the impact of field outlet locations on transportation distances is minimized; and outlets can be located based on existing facilities and ease of operation. Extending the study to other field shapes (e.g., circular, quadrilateral), comparing with automatic multi-bale picker $(\approx 35 \%$ less total distance) for stack formation and direct aggregation to the outlet, and evaluating the economics of aggregation and transportation scenarios involving subfield stacks with appropriate bale handling equipment might constitute further research opportunities.

\section{Acknowledgements}

This work supported in part by the USDA National Institute of Food and Agriculture, Hatch Project: ND01472, Accession number: 229896. Typing of parts of the manuscript and discussion support extended by I. Srividhya is also appreciated.

\section{Supplementary material}

Supplementary material related to this article can be found at http://dx . doi .org/10.1016/ j.biombioe.XXXX.XX.XXX.

\section{Disclaimer}

NDSU, INL, UNL, and USDA/ARS are equal opportunity providers and employers. 


\section{References}

[1] C.R. Dumas, Analysts: Hay prices at point of no return, Capital Press, The West's Ag Weekly [Cited 2016 April 06]., 2015. URL: http: //www . capitalpress . com/Nation_ World/Nation/20150219/analysts-hay-prices-at-point-of-no-return.

[2] USDA, Crop Production 2014 Summary - January 2015, United States Department of Agriculture, National Agricultural Statistics Service, 2014 Agricultural Statistics Annual [Cited 2016 April 06], pp. 30-31., 2014. URL: http://www . usda.gov/nass/PUBS/ TODAYRPT/cropan15.pdf.

[3] R.D. Perlack, A.F. Turhollow, Assessment of options for the collection, handling, and transport of corn stover, Oak Ridge National Laboratory, Oak Ridge, Tennessee, 2002.

[4] S. Sokhansanj, A. Kumar, A.F. Turhollow, Development and implementation of integrated biomass supply analysis and logistics model (IBSAL), Biomass Bioenergy 30 (2006) 838-847.

[5] A. Kumar, S. Sokhansanj, Switchgrass (Panicum vigratum, L.) delivery to a biorefinery using integrated biomass supply analysis and logistics (IBSAL) model, Bioresour. Technol. 98 (2007) 1033-1044.

[6] J.E. Carolan, S.V. Joshi, B.E. Dale, Technical and financial feasibility analysis of distributed bioprocessing using regional biomass pre-processing centers, J. Agric. Food Ind. Organiz. 5 (2007).

[7] R.V. Morey, N. Kaliyan, D.G. Tiffany, D.R. Schmidt, A corn stover supply logistics system, Appl. Eng. Agric. 26 (2010) 455-461.

[8] J.S. Cundiff, R.D. Grisso, Containerized handling to minimize hauling cost of herbaceous biomass, Biomass Bioenergy 32 (2008) 308-313.

[9] D.R. Petrolia, The economics of harvesting and transporting corn stover for conversion to fuel ethanol: A case study for Minnesota, Biomass Bioenergy 32 (2008) 603-612.

[10] D.E. Cook, K.J. Shinners, Economics of alternative corn stover logistics systems, in: 2011 Louisville, Kentucky, August 7-10, 2011, American Society of Agricultural and Biological Engineers, 2011.

[11] J.S. Cundiff, R.D. Grisso, D. McCullough, Comparison of bale operations for smaller production fields in the southeast, in: 2011 Louisville, Kentucky, August 7-10, 2011, American Society of Agricultural and Biological Engineers, 2011.

[12] D. Bochtis, C. Sørensen, The vehicle routing problem in field logistics: Part I, Biosyst. Eng. 104 (2009) 447-457.

[13] D. Bochtis, C. Sørensen, The vehicle routing problem in field logistics: Part II, Biosyst. Eng. 105 (2010) 180-188.

[14] D.D. Bochtis, C.G. Sørensen, P. Busato, Advances in agricultural machinery management: A review, Biosyst. Eng. 126 (2014) 69-81.

[15] R.D. Grisso, J.S. Cundiff, D.H. Vaughan, Investigating machinery management parameters with computer tools, ASABE Paper No. 071030. St. Joseph, MI: ASABE, 2007. 
[16] C. Gracia, B. Diezma-Iglesias, P. Barreiro, A hybrid genetic algorithm for route optimization in the bale collecting problem, Spanish J. Agric. Res. 11 (2013) 603-614.

[17] C. Igathinathane, D. Archer, C. Gustafson, M. Schmer, J. Hendrickson, S. Kronberg, D. Keshwani, L. Backer, K. Hellevang, T. Faller, Biomass round bales infield aggregation logistics scenarios, Biomass Bioenergy 66 (2014) 12-26.

[18] R Core Team, R: A Language and Environment for Statistical Computing, R Foundation for Statistical Computing, Vienna, Austria, 2015. URL: http://www.R-project .org/. 
List of Tables

1 ANOVA of subfield stack parameters on the infield logistics distances. . . . . . . 19

Effect of field variables on the number of subfield stacks and logistics for a corner outlet (O:D) and stacks at the middle (M) of subfields. . . . . . . . . 20 
Table 1

ANOVA of subfield stack parameters on the infield logistics distances.

\begin{tabular}{lllllll}
\hline Variable & Parameter & $d f$ & MeanSq & $F$ & $p$ & Significance \\
\hline Aggregation & Outlet location & 3 & 1 & 0.0 & 1.00 & \\
& Stack location & 3 & 173862 & 262.7 & $<2.00 \mathrm{e}-16$ & $* * *$ \\
& Stack number & 2 & 1796858 & 2715.0 & $<2.00 \mathrm{e}-16$ & $* * *$ \\
& Bales/trip & 7 & 0 & 0.0 & 1.0 & \\
& Residuals & 368 & 662 & & & \\
\hline Transportation & Outlet location & 3 & 16624 & 10.6 & $1.03 \mathrm{E}-06$ & $* * *$ \\
& Stack location & 3 & 1059 & 0.7 & 0.57 & \\
& Stack number & 2 & 16383 & 10.5 & $3.79 \mathrm{E}-05$ & $* * *$ \\
& Bales/trip & 7 & 273465 & 174.7 & $<0.22 \mathrm{E}-16$ & $* * *$ \\
& Residuals & 368 & 1565 & & & \\
\hline Total & Outlet location & 3 & 16434 & 7.0 & 0.00 & $* * *$ \\
& Stack location & 3 & 147844 & 63.4 & $<2.20 \mathrm{E}-17$ & $* * *$ \\
& Stack number & 2 & 1471340 & 631.1 & $<2.20 \mathrm{E}-16$ & $* * *$ \\
& Bales/trip & 7 & 273678 & 117.4 & $<2.20 \mathrm{E}-18$ & $* * *$ \\
& Residuals & 368 & 2331 & & & \\
\hline
\end{tabular}

Note: Basic data used in the ANOVA and the underlying assumptions are from Figure 7, with additional data for bales/trip; outlet and stack locations are D, W, L, and M (Fig. 3); $d f$ - degrees of freedom; significance levels: blank - not significant or significant at $p=1.0$, and $* * *$ - significant at $p=0.001$. 


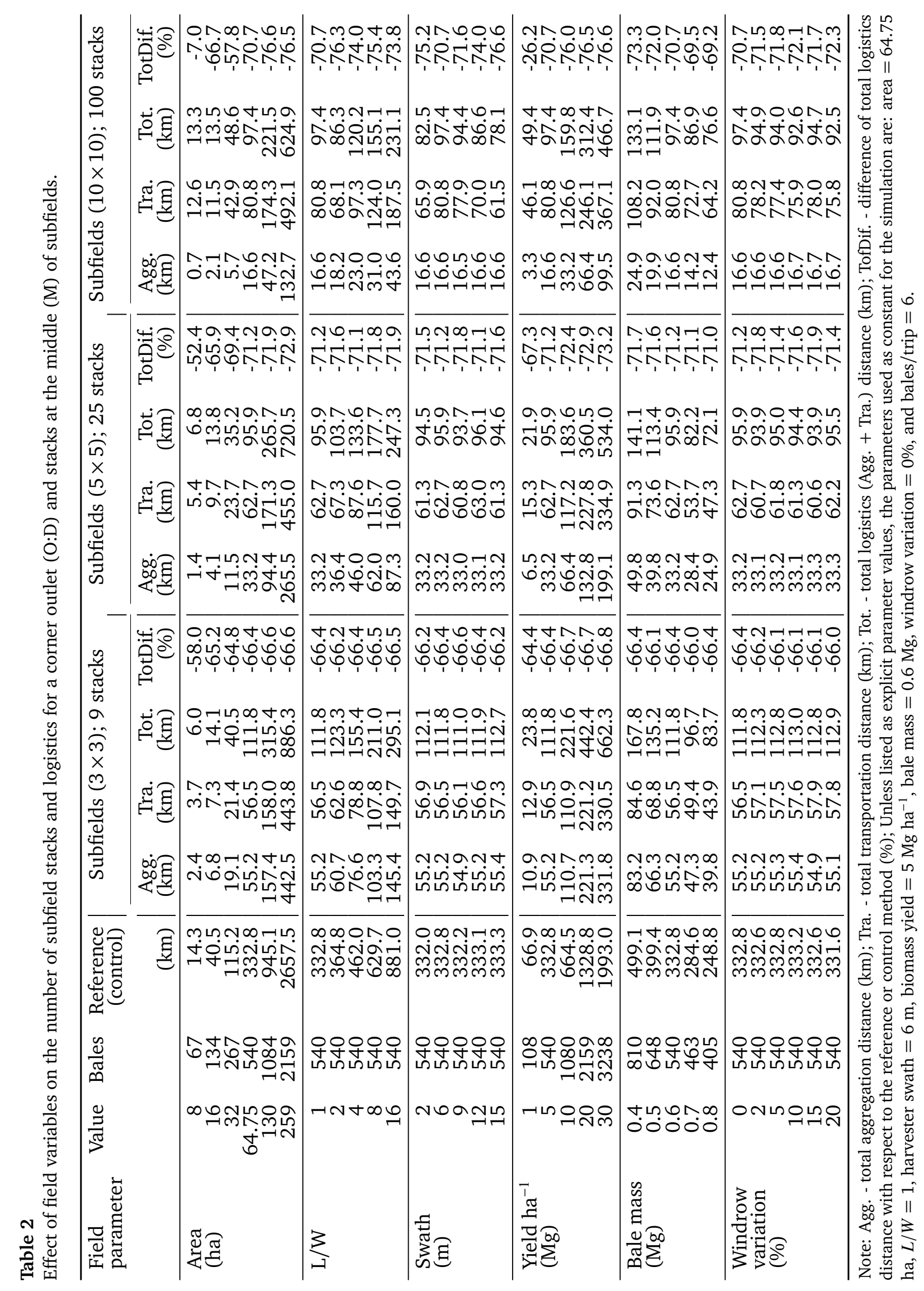




\section{List of Figures}

1 Biomass bales remain distributed on (A) field and (B) in subfield stacks made after aggregation (aerial view) and (C) at the field outlet before they are transported to final use. . . . . . . . . . . . . . . . . . . 22

2 Bale aggregation distances (data points) to subfield stacks as affected by stack locations along specified paths (colored arrows) and the stacks location ranking. Simulation parameters used: area $=64.75$ ha (field dimensions ( $L=1138 \mathrm{~m}$, $W=569 \mathrm{~m}$ ) not shown), $L / W=2$, swath width $=6 \mathrm{~m}$, biomass yield $=12$ $\mathrm{Mg} \mathrm{ha}^{-1}$, bale mass $=0.6 \mathrm{Mg}$, windrow variation $=10 \%$, number of subfields $=$ 1 , and number of bales $=1295 . \ldots \ldots \ldots \ldots$

3 Subfield stacks and field outlets location layouts studied for infield bale logistics. Green circles $=$ bales, black grids $=$ subfield boundaries, purple circles $=$ subfield stacks, yellow squares $=$ field outlets, and red arrows $=$ bale aggregation direction. Letters represent subfield/field location such as $\mathrm{O}=$ outlet, $\mathrm{D}=$ diagonal corner, $\mathrm{W}=$ mid-edge width, $\mathrm{L}=$ mid-edge length, and $\mathrm{M}=$ middle. The first four subfigures illustrate layouts with corner field outlet (O:D) with subfield stacks at: (a) corner (D), (b) mid-edge width (W), (c) mid-edge length, and (d) field middle (M). The fifth subfigure (e) illustrates the other possible outlet combinations with the above subfield stack locations. Simulation parameters used were similar to Figure 2, but number of subfields $=9(3 \times 3)$, biomass yield $=5 \mathrm{Mg} \mathrm{ha}^{-1}$, and number of bales $=540 \ldots \ldots \ldots \ldots$. . . . . . . . . . . 24

4 Effect of subfield stack and field outlet locations on logistics for the bales layout illustrated in Fig. 3 with fixed corner field outlet (O:D) for two field shapes ( $L / W=1$ - colored symbols and lines, and $L / W=2$ gray circles and lines) and various number of transported bales/trip. . . . . . . . . . . . . . . . 25

5 Total logistics distances to four field outlets as affected by the stack locations along the best diagonal aggregation path. Simulation parameters used were same as Figure 2. Legend: Aggregation = total aggregation distance for 50 stack locations along the diagonal path indicated, Total:D1 = total logistics distance to outlet D using 1 bale/trip from the 50 stack locations along the diagonal, and Total:W6 $=$ total logistics distance to outlet W using 6 bales/trip, and so on. . . 26 Effect of (a) the number of subfield stacks ( 6 bales/trip assumed) and (b) bales/trip $(4 \times 4=16$ subfields assumed) used in transportation on logistics distances for different outlets. Common simulation parameters used: area $=$ 64.75 ha, $L / W=1$, swath width $=6 \mathrm{~m}$, biomass yield $=5 \mathrm{Mg} \mathrm{ha}^{-1}$, bale mass $=$ $0.6 \mathrm{Mg}$, windrow variation $=0 \%$, and number of bales $=540 \ldots \ldots$. . . . . 27

7 Bale collection logistics components showing the effects of bale stack and field outlet locations with the number of subfield stacks and the number of transported bales/trip. Panel head labels represent the combination of outlet and number of stacks (e.g., O:D-S:1 = corner outlet (D) and 1 bale stack, O:W-S25 = mid-width outlet (W) and 25 bale stacks, and so on). Dotted lines represent the reference method. Simulation parameters used: area $=64.75$ ha, $L / W=2$, swath width $=6 \mathrm{~m}$, biomass yield $=5 \mathrm{Mg} \mathrm{ha}^{-1}$, bale mass $=0.6 \mathrm{Mg}$, windrow variation $=$ $10 \%$, and number of bales $=540$. 


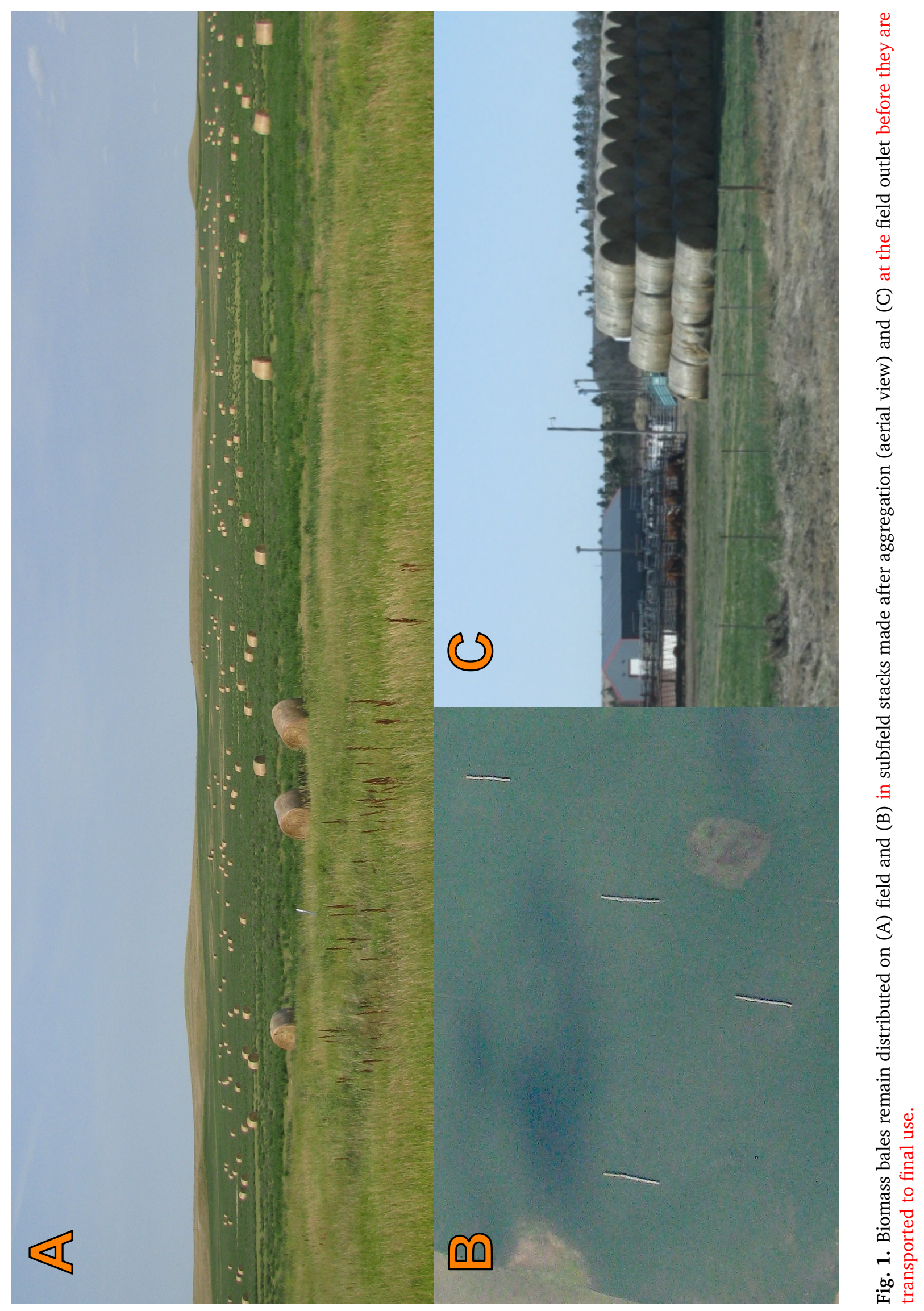




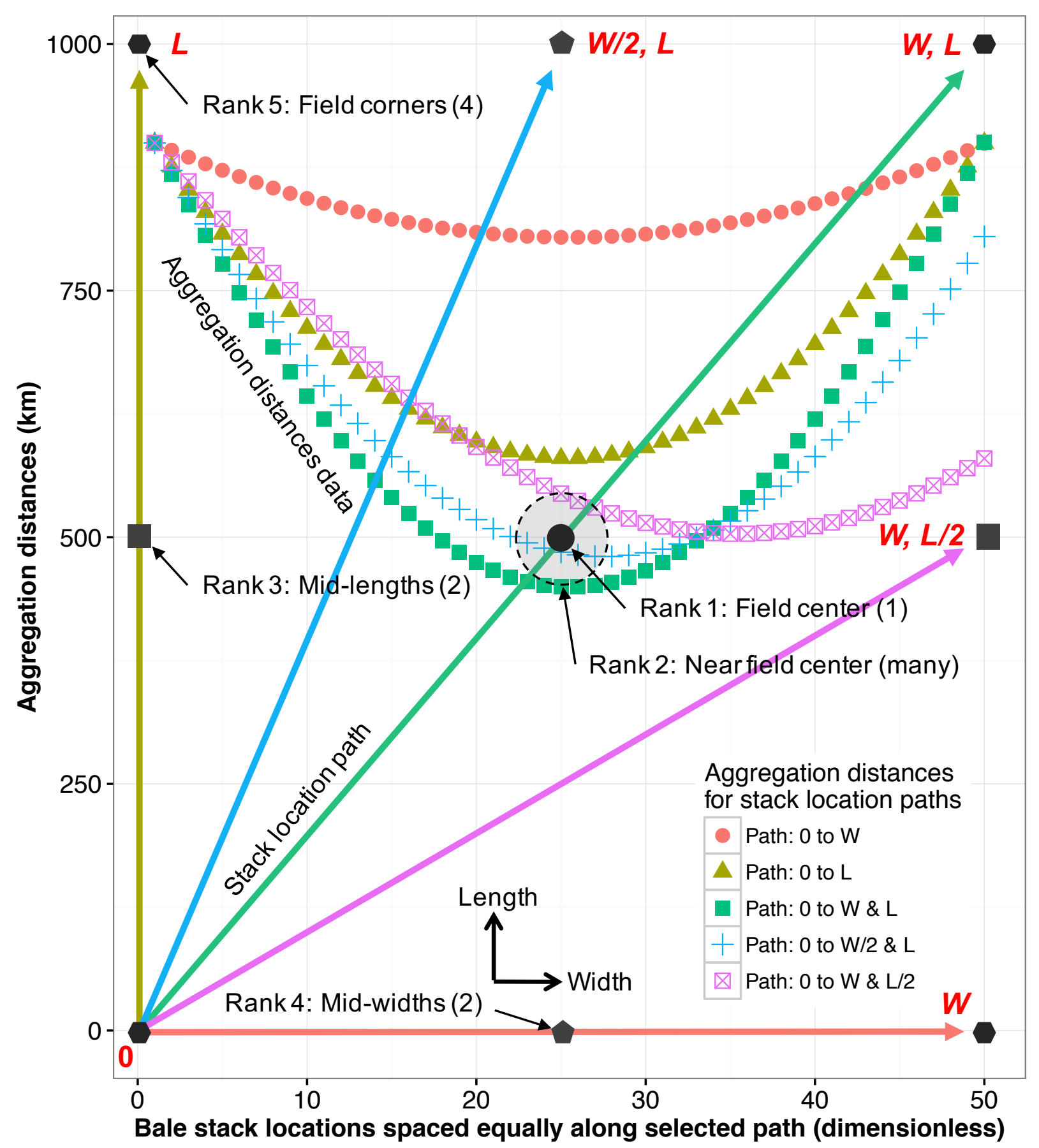

Fig. 2. Bale aggregation distances (data points) to subfield stacks as affected by stack locations along specified paths (colored arrows) and the stacks location ranking. Simulation parameters used: area $=64.75$ ha (field dimensions ( $L=1138 \mathrm{~m}, W=569 \mathrm{~m}$ ) not shown), $L / W=2$, swath width $=6 \mathrm{~m}$, biomass yield $=12 \mathrm{Mg}^{-1}$, bale mass $=0.6 \mathrm{Mg}$, windrow variation $=10 \%$, number of subfields $=1$, and number of bales $=1295$. 

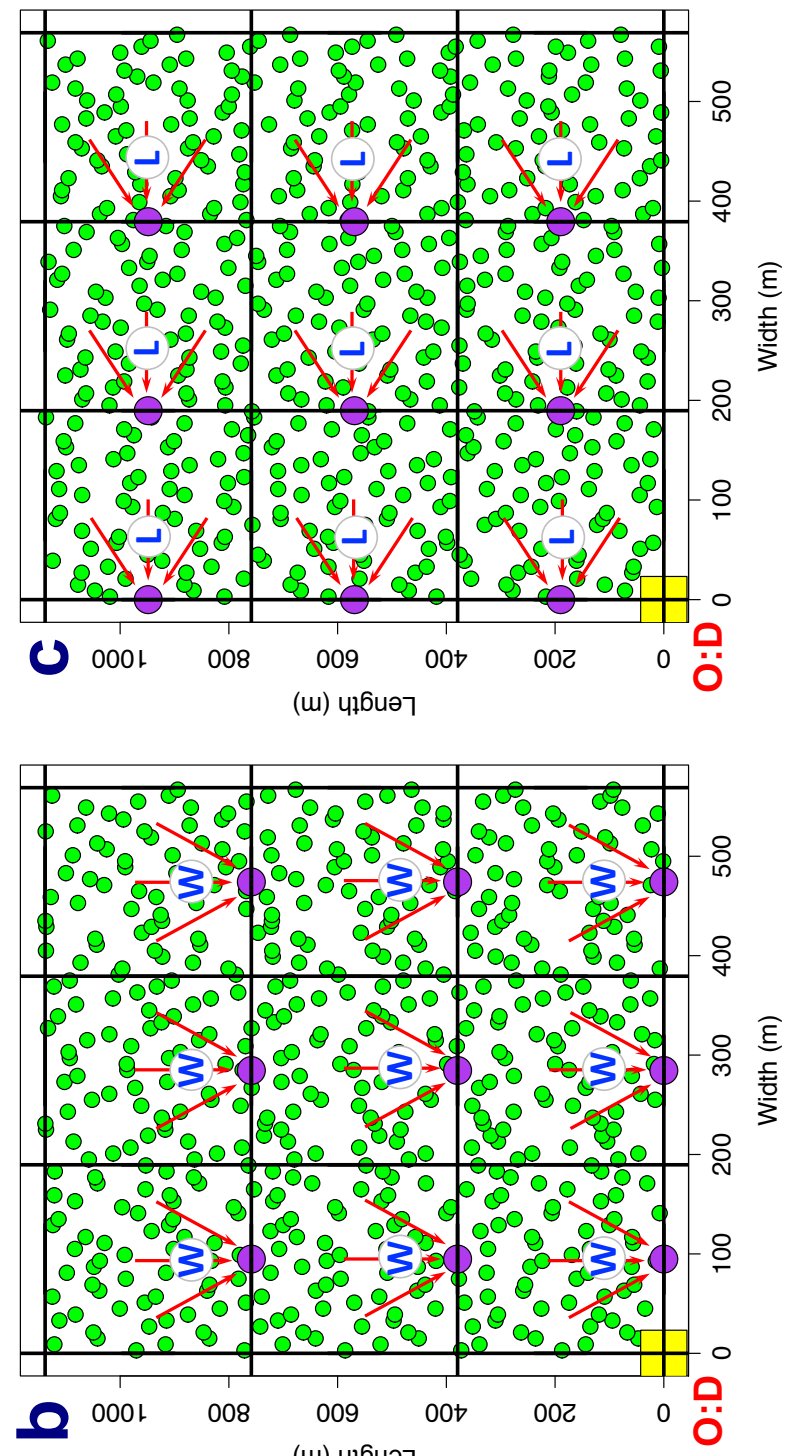

(ш) ч‡ธนәา

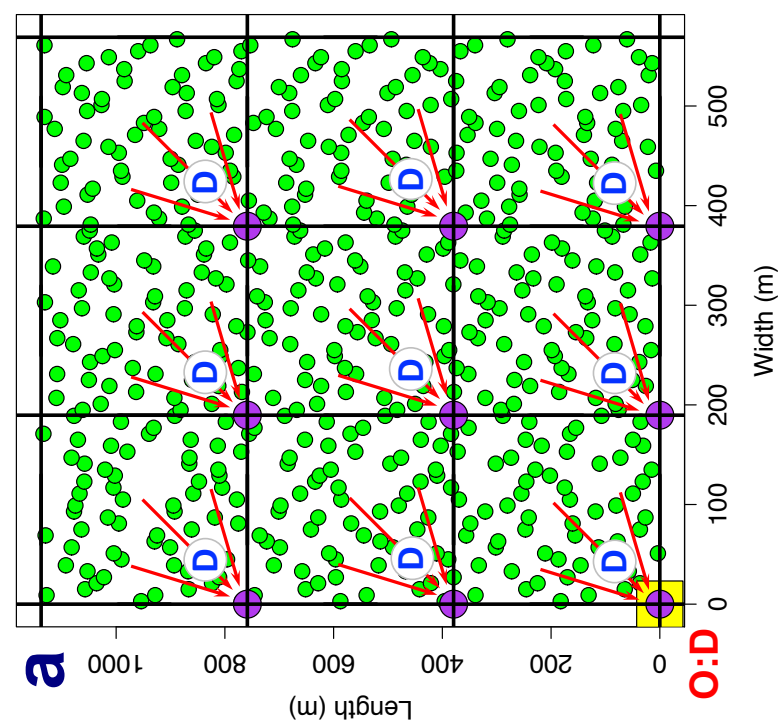

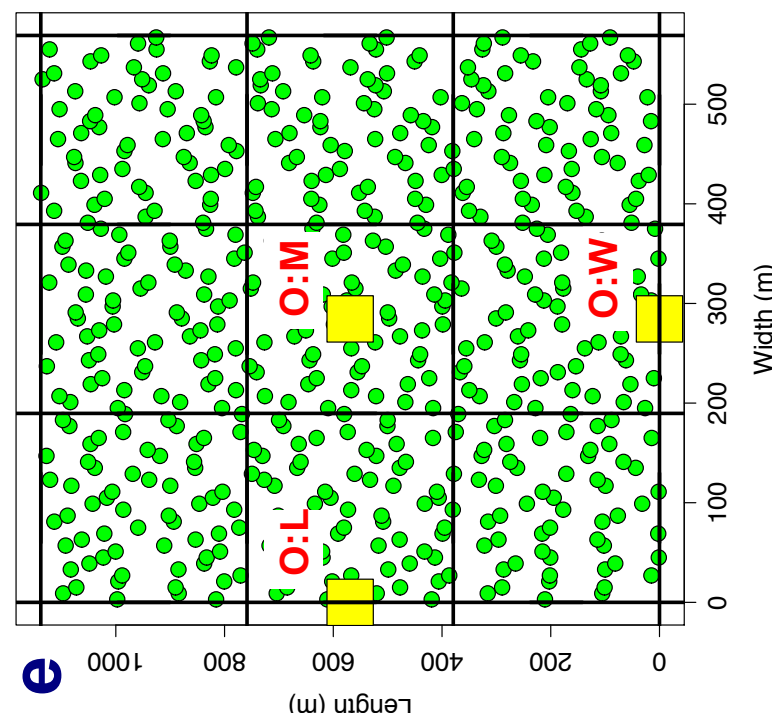

(i) чұбиәך

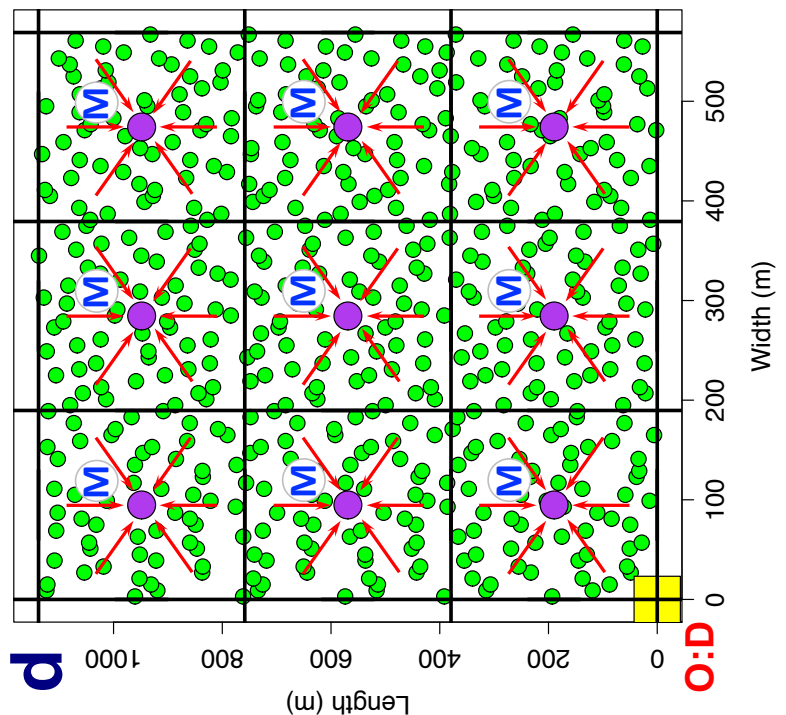

(u) ч1биәา

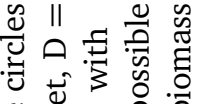

录合

월

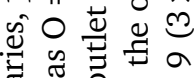

준요 \&

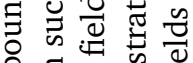

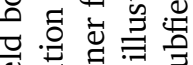

式

के च 듕

11 \& 500

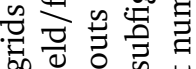

叫进忩的节

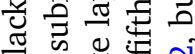

亖苞导

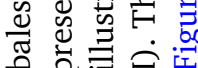

11 क 过

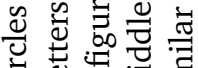

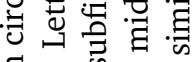

षี के 휴

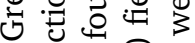

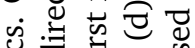

诃证

.

으륱ㄹㅇ

(1)

○

幽

.

ర어

प 各

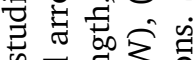

क पृ

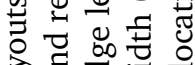

청 융요

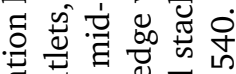

ปั

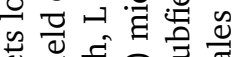

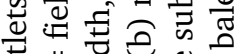

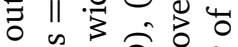

융 Ð

记 它 声

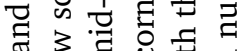

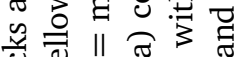

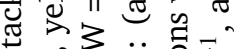

क ज्ञ

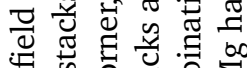

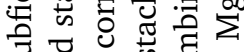

क च

ம்

क. 


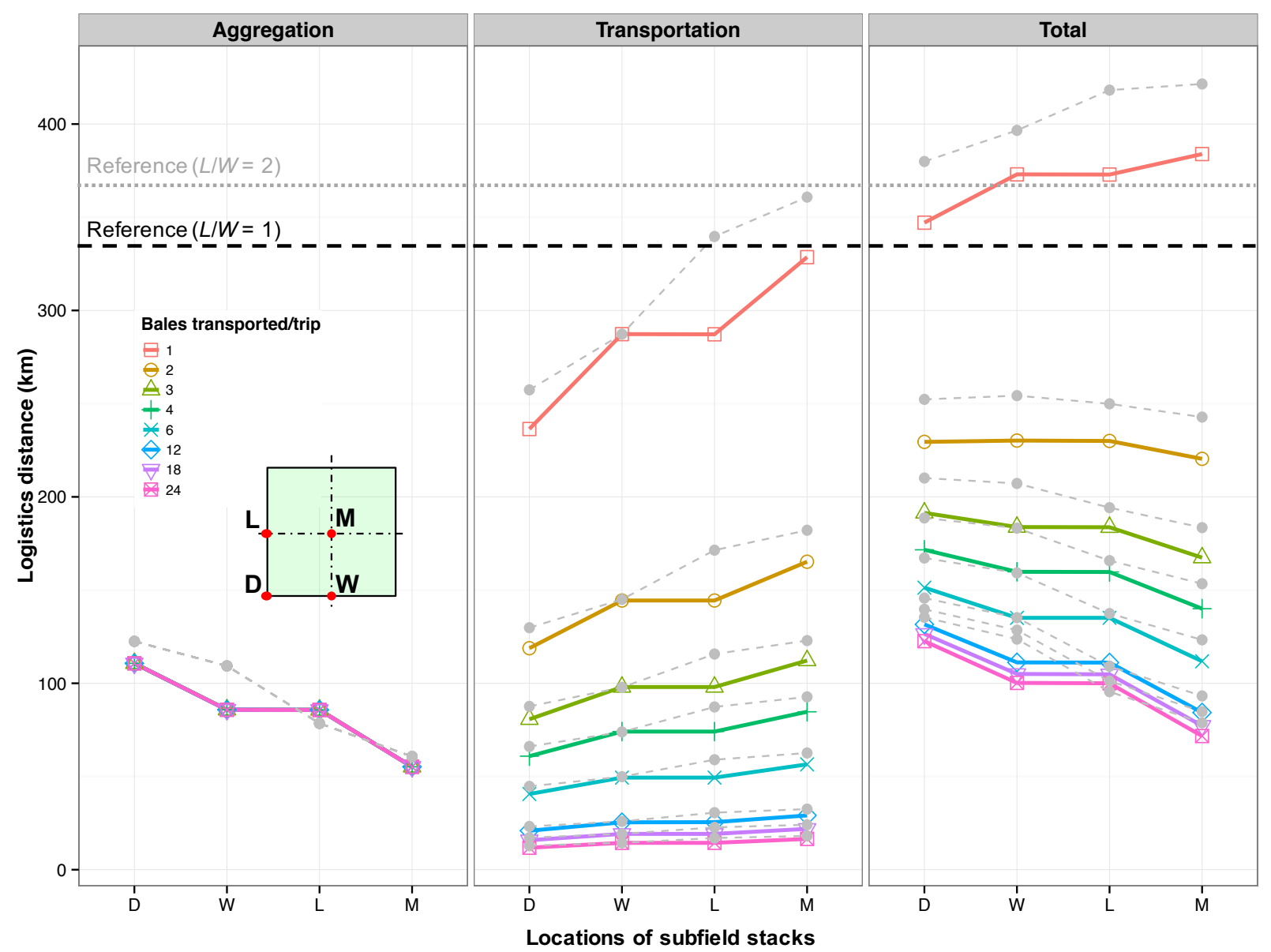

Fig. 4. Effect of subfield stack and field outlet locations on logistics for the bales layout illustrated in Fig. 3 with fixed corner field outlet (O:D) for two field shapes ( $L / W=1$ - colored symbols and lines, and $L / W=2$ gray circles and lines) and various number of transported bales/trip. 


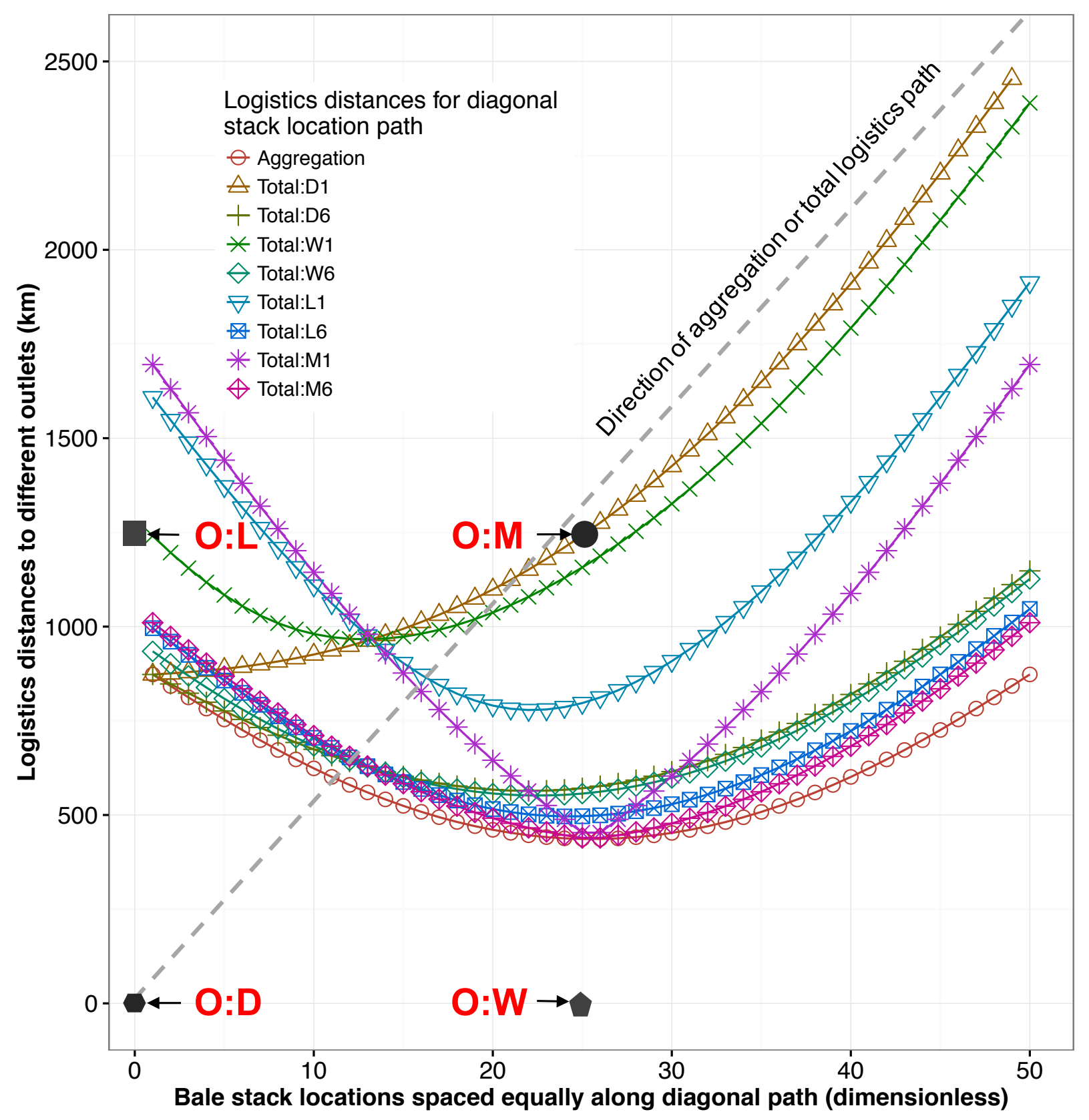

Fig. 5. Total logistics distances to four field outlets as affected by the stack locations along the best diagonal aggregation path. Simulation parameters used were same as Figure 2. Legend: Aggregation $=$ total aggregation distance for 50 stack locations along the diagonal path indicated, Total:D1 = total logistics distance to outlet D using 1 bale/trip from the 50 stack locations along the diagonal, and Total:W6 = total logistics distance to outlet W using 6 bales/trip, and so on. 


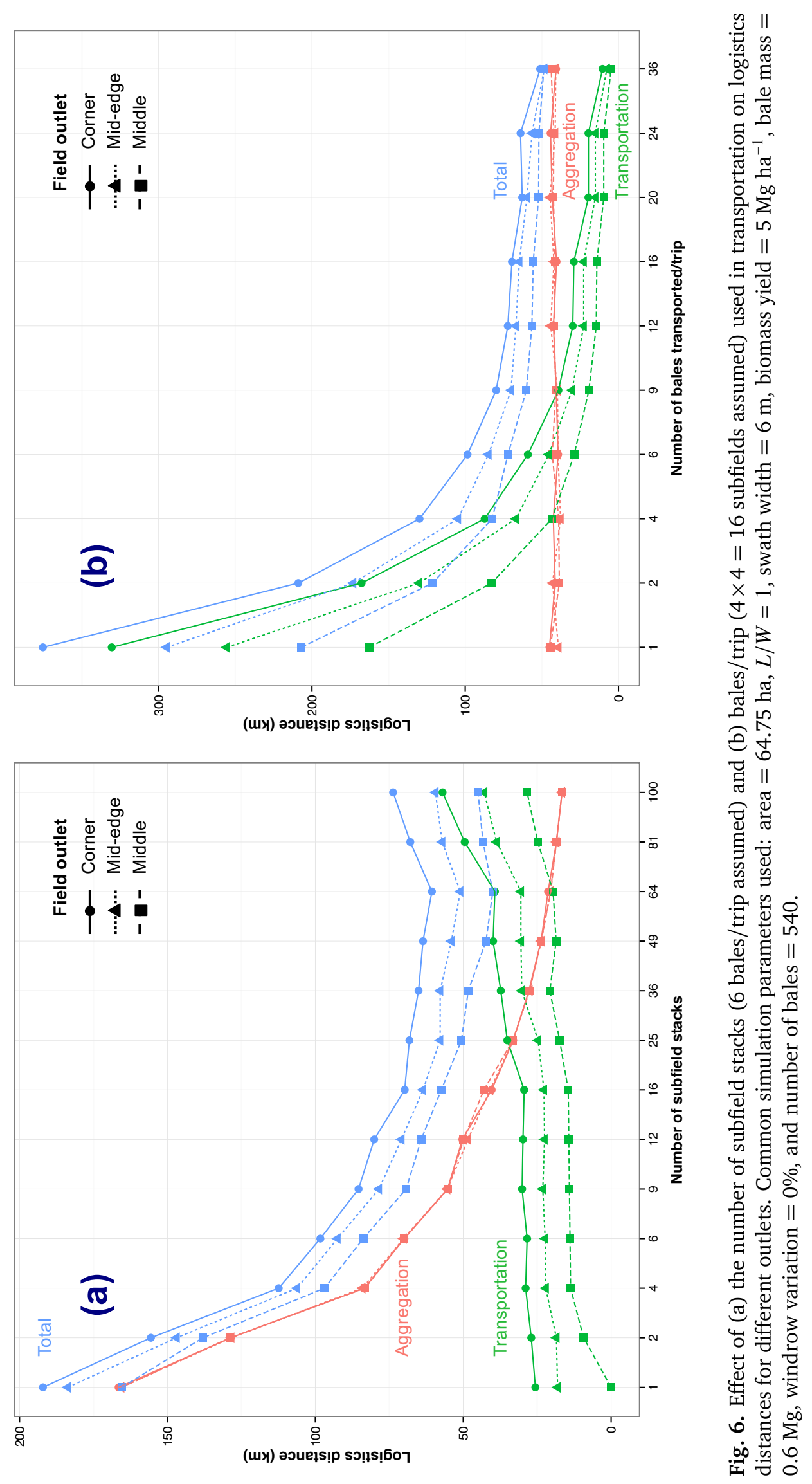



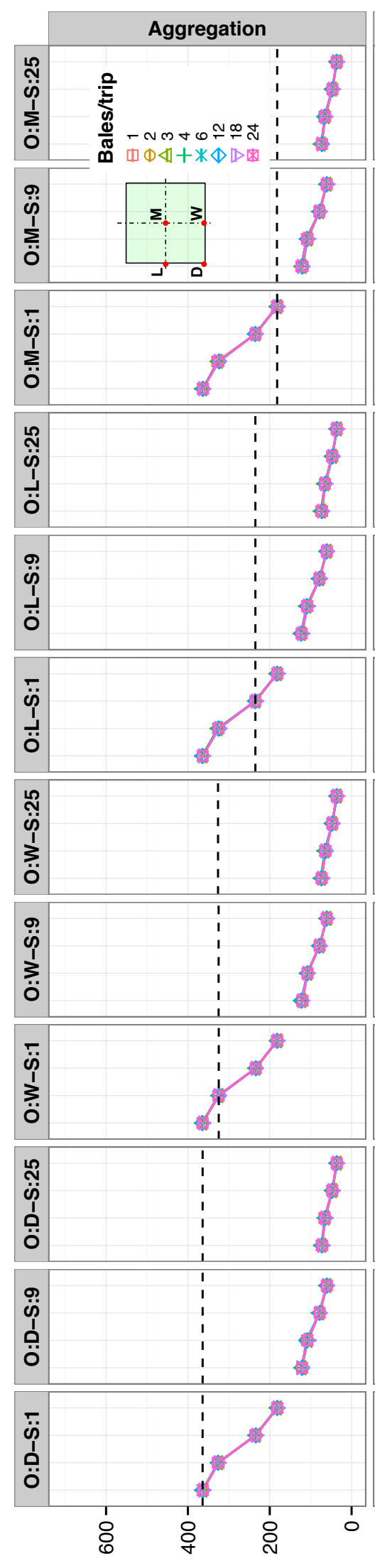

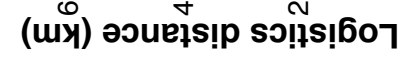
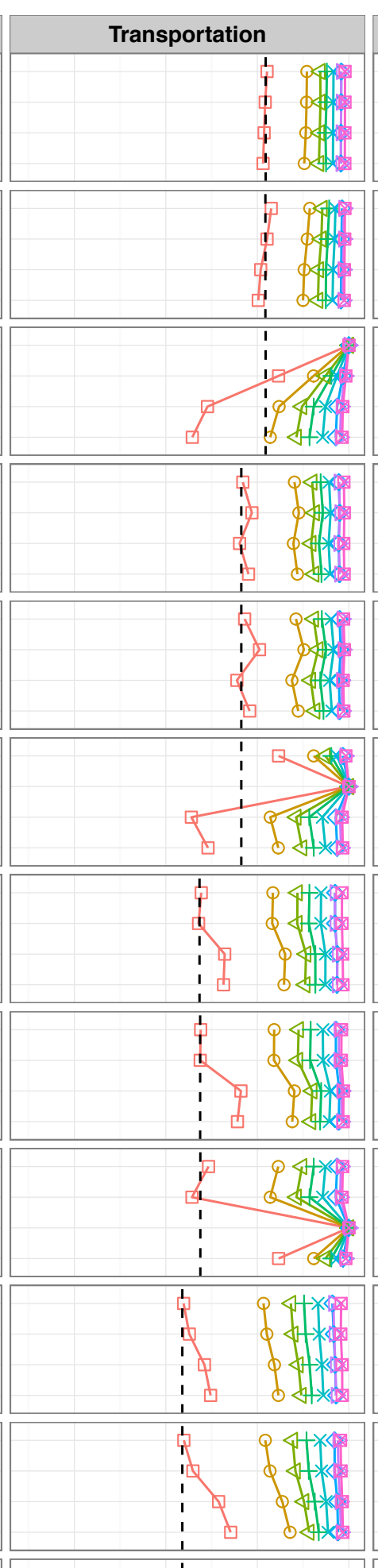
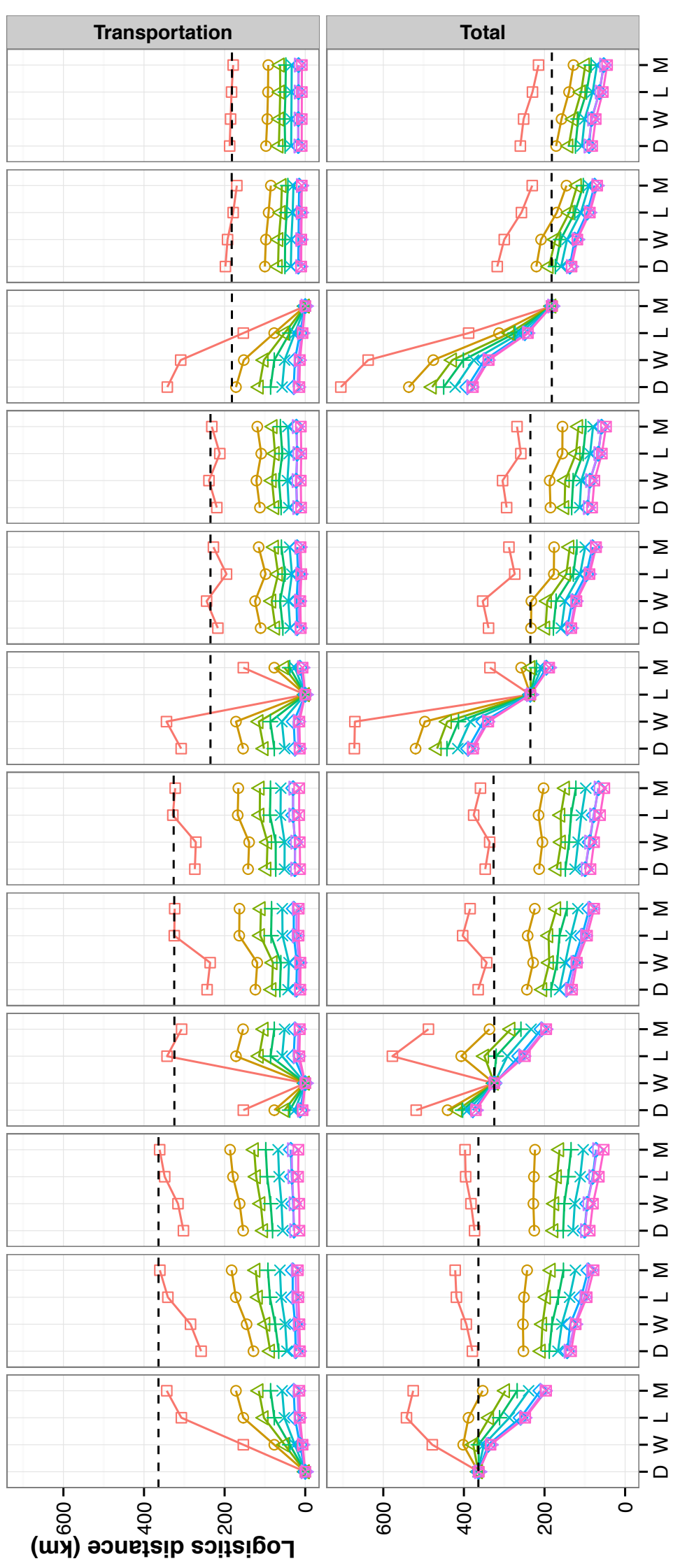
Graphical Abstract

\section{Graphical abstract}
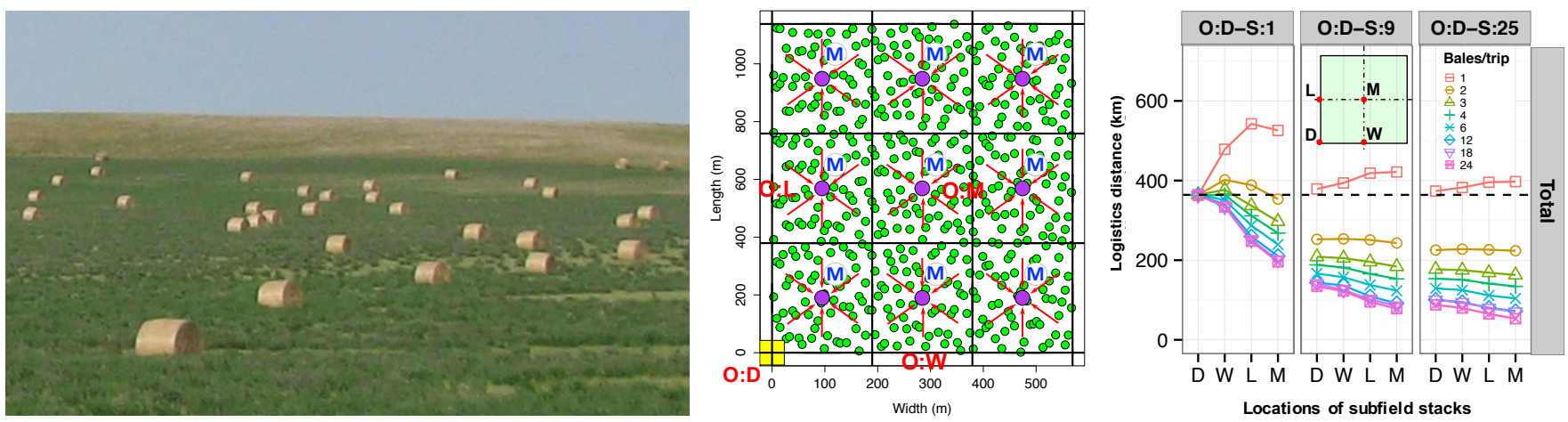